\title{
Asset Classification, Subsequent Measurement and Impairment Testing for Carbon Emission Trading
}

\author{
Tharatee Mookdee - Sheila Bellamy*
}

\begin{abstract}
:
With global efforts to combat climate change, accountants from participating entities worldwide need to report the economic value of carbon credits and related assets in carbon markets. However, the absence of formal accounting guidelines allows the selection of accounting practices and reporting methods based on individual judgment. Also, emitters are allowed to invest in carbon credit projects and trading. These circumstances have led to diversity in global accounting practices. As accounting is an international business language in a global business world, it is important to study emerging accounting practices for carbon emission trading. The main aim of this study is, therefore, to explore the accounting practices (asset classification, subsequent measurement and impairment testing) of carbon credit providers/traders. Sample companies from Australian mandatory and voluntary carbon markets were selected. The study was conducted using case-study methodology and in-depth interviews, supported by archival and secondary data. It was found that the preferred asset classification of carbon credits varies among case-site participants, according to specific market requirements and economic uncertainty. Valuation methods differ across sites due to internal operations and economic factors. Impairment testing requires reference price indices determined by the nature of assets and professionals.
\end{abstract}

Key words: Financial accounting; Emission trading; Emission rights; Accounting standards, EU ETS.

JEL classification: M41.

\section{Introduction}

The emerging consensus - as seen in the United Nations Framework Convention on Climate Change (UNFCCC) and the Kyoto Protocol to tackle global climate change and the emergence of carbon markets - have triggered accounting and reporting implications (Raiborn and Massoud (2010, p.109). Given the absence of formal guidelines for carbon emissions trading worldwide, market participants are allowed to select accounting and reporting practices based on individual judgment.

\footnotetext{
Tharatee Mookdee; Uttaradit Rajabhat University, Faculty of Management Science, Department of Accounting, 27 Inchaimee Road, 53000, Uttaradit, Thailand, <tharatee@ hotmail.com>.

Sheila Bellamy; RMIT University, College of Business, School of Accounting and Law, 445 Swanston Street, Melbourne, 3000, Victoria, Australia, <sheila.bellamy@ rmit.edu.au>.

The article is processed as a partial output of a research project Accounting for Carbon Emission Trading: An Australian Perspective.
} 
Mookdee, T. - Bellamy, S.: Asset Classification, Subsequent Measurement and Impairment Testing for Carbon Emission Trading.

Also, emitters are allowed to be carbon credit providers/traders or invest in forest carbon sinks (GGAS, 2011). As Accounting is an international business language in global business community, accounting people are, thus, sharing the same burden in emerging carbon markets. The need to clearly and unambiguously communicate relevant financial information to users therefore becomes necessary, and a clear understanding of emerging accounting practices for carbon emissions trading schemes (ETS) is important.

This research follows the financial accounting practices for carbon emissions trading in Australia. In particular, this study contributes to the literature worldwide with a focus on asset recognition and classification, subsequent measurement, impairment testing, revenue and expense recognition, accounting change, and accounting policy disclosure practices. The case companies were selected from market participants who have developed accounting practices covering these all issues. While the accounting practices of the benchmark participants and carbon credit providers in both mandatory and voluntary markets from 2005-2012 were reviewed as potential participants, it was only the forest carbon credits providers ( 3 out of 144 carbon credit providers under the New South Wales Greenhouse Gas Reduction Schemes, GGAS) and voluntary market who have been practicing all elements of accounting practices, were selected as the case participants.

\section{Literature review}

Given that accounting is the global business language, it is important to review related formal guidelines worldwide. In the market, all types of carbon credit/emission allowance including credits/allowances created from utilities sectors are equal (one carbon credit $=$ one tone of carbon dioxide that would otherwise release to the atmosphere). On the other hand, these emission allowances may be obtained through an allocation from a regulatory body at no cost or at a cost that is less than fair value, through an auction process, or through an exchange (a purchase from other market participants such as a benchmark participant emitter, emission allowance/abatement certificate providers, brokers or aggregators).

The accounting guidelines above classify emissions allowances into two main groups: granted (allocated) or created emissions allowances and purchased emissions allowances. This section, chronologically outlines and discusses guidelines and point of views from accounting bodies, agencies, academics and professionals.

Some accounting bodies previously provided guidance on financial reporting for carbon credits, but later withdrew the guidance because of widespread criticism from the broader accounting fraternity about its contradictory nature. 
Contradictions arise from the debate between classifying carbon credits as intangible assets (IFRIC 3) versus the inventory classification proposed by the Emerging Issues Task Force (EITF). In addition, issues arise in relation to not only classification, but timing, valuation and other impacts on financial reports (IETA/Pwc, 2007; Elfrink \& Ellison, 2009; Lovell et al., 2010).

In 2003, the EITF addressed emissions accounting issues in the EITF Issue 03-14, Participants' Accounting for Emissions Allowances under a "Cap and Trade" program ${ }^{1}$, used by utilities and other energy companies. Emissions allowances are to be reported at historical cost and classified as inventory, purchased allowances are to be recorded at their exchange price, while those received (granted) from the US Environmental Protection agency (EPA) are recorded as no charge and have a zero basis. The weighted-average cost method is required, with monthly calculations. Periodic expense is recognized based on the historical cost of allowances needed to satisfy actual emissions of sulphur dioxide during the period (Fornaro et al, 2009).

In relation to the notion that emissions allowances should be treated as assets, the EITF considered 4 views in their deliberations: (1) Emissions allowances are intangible assets as defined by the Statement of Financial Accounting Standard ("SFAS") No. 142, Goodwill and Other Intangible Assets, because they lack physical substance; (2) The allowances are financial assets because markets for emissions trading provide evidence that allowances are readily convertible to cash. Deloitte \& Touche LLP (Deloitte) and PricewaterhouseCoopers LLP (PwC) agreed with this view despite the fact that emissions allowances do not meet the definition of a financial asset under SFAS 140, Transfers and Servicing of Financial Assets and Extinguishments of Liabilities; (3) Emissions allowances are inventory as they are the necessary costs incurred to comply with environmental regulations and emissions reduction schemes; as noted, this categorisation was adopted by the EITF; (4) The nature of the asset depends on the intended use of the emissions allowances by the entity, with it being treated as an intangible asset or inventory if used for operational purposes, and as a financial asset if used for trading purposes (Deloitte, 2007). However, some EITF members were concerned with the compatibility of the Federal Energy Regulatory Commission (FERC)'s requirements and other areas of US GAAP, which might cause certain accounting anomalies. In the US, a large percentage of emissions allowances are allocated by the Environmental Protection Agency (EPA), a government agency on a zero cost basis. FERC guidelines can distort the economic reality of liable US companies (Forano et al., 2009).

The cap and trade program is an emissions control program where the government imposes the limit (or 'cap') of emissions to emitters and allows them to trade unused portions of these caps. 
Mookdee, T. - Bellamy, S.: Asset Classification, Subsequent Measurement and Impairment Testing for Carbon Emission Trading.

In December 2004, the International Financial Reporting Interpretation Committee (IFRIC) issued IFRIC 3 Emissions Rights, but it was withdrawn by the International Accounting Standards Board (IASB) the following year. The rationale for its withdrawal is discussed later in this section. The key points of this guidance were: Emissions allowances are considered intangible assets under IAS 38 Intangible Assets, which permits a revaluation method where shareholders' equity is reported when fair value increases, and the excess of revaluation surplus in the profit and loss statement is recognized when fair value decreases (revaluation model); Moreover, IAS 38 also permits the historical cost model as the other accounting choice. Entities can carry the intangibles at cost or at fair value to the extent that there is an active allowance market; Allowances purchased are recorded at cost. Allowances or certificates received from a government body are recorded at no cost or for less than fair value and reported at fair value when received; the difference between price paid and the fair value of allowances received from the government is initially reported as deferred income. This difference is recognized as revenue over the compliance period, no matter whether they are held or sold (follow IAS 20 Accounting for Government Grants and Disclosure of Government Assistance); No permission to offset assets and liabilities (right of set-off) related to emissions. Follow the guidance in IAS 37 Provisions, Contingent Liabilities and Contingent Assets in order to recognize liabilities and expenses. With the issuance of IFRIC 3, the IASB followed Wambsganss and Sanford's (1996) view that emissions, in general, be recognised at market value (Bebbington \& Larrinaga-Gonza'lez, 2008). Some critics of the approach argued that this failed to substantiate their assertion that markets could function more efficiently relative to the cost of pollution if emissions costs were recognized in balance sheets and income statements, since these emissions allowances reflect only the cost of the permission to pollute not an economic cost of pollution (Gibson, 1996).

The European Financial Reporting Advisory Group (EFRAG) was concerned about the effect of the application of IFRIC 3 because it did not, in its view, represent economic reality; nor did it meet the criteria of an understandability, relevance, reliability and comparability required of financial statements needed for economic decision-making. Moreover, IFRIC's interpretation was constrained by the interplay of existing standards (IAS 38, IAS 20 and IAS 37). Where entities had not acquired or sold emissions allowances, applying IFRIC 3 created a measurement mismatch whereby some items were measured at cost (IAS 38 and IAS 20) while others were measured at fair value. It also created a reporting mismatch since some gains and losses were recognized in the income statement (IAS 20 and IAS 37) and some were recognized in equity (IAS38). Adding their voice to those of the critics, Krupova' and Černy' (2007) noted that allowances 
were recognized when they were obtained, whereas the liability was recognized over the time it was incurred, thus there was a timing mismatch; this caused volatility in the operating result, even if the entity did not sell granted allowances at all. Furthermore, the measurement of allowances did not reflect market price. In addition, due to the measurement and reporting mismatches, IFRIC 3 failed the tests of relevance and reliability according to the IASB framework as well as the regulations of the European Parliament and Council (Moore, 2010). IFRIC 3 also attracted complaints from companies that its application would force the former into showing a distorted performance in their annual and interim financial statements (Cook, 2009). Given its concerns, EFRAG recommended that the EU Commission not endorse IFRIC 3, EFRAG, (2005). Although the standard was subsequently withdrawn, the overall effect of its application still exists even though the compliance period is over (IETA/PwC, 2007). Moreover, the withdrawal of IFRIC 3 means that there is an absence of an accounting discourse with regards to emissions trading, evidencing a critical situation (Moore, 2010).

In 2005, the Australian Accounting Standards Board (AASB) issued an Urgent Issues Group 3 (UIG 3) Emissions rights and Renewable energy certificate corresponding to IFRIC 3; this was withdrawn several months after the demise of IFRIC 3. This interpretation dealt with how to account for a 'cap and trade' emissions rights scheme. It identified the features of emissions trading schemes, the options of participants to meet the scheme's requirements, the scope of interpretation, relevant accounting issues and their consensus. The key issues of this interpretation are as follows: Purchased allowances and allowances issued by the government are intangible assets that shall be accounted for in accordance with AASB 138. Allowances that are issued for less than fair value shall be measured initially at their fair value; where allowances are issued for less than fair value, the difference is a government grant that is within the scope of AASB 120 Accounting for Government Grants and Disclosure of Government Assistance. The grant shall be recognised initially as deferred income in the balance sheet and systematically recognised in deferred income over the compliance period for which the allowances were issued, regardless of whether the allowances are held or sold; a liability is recognised when there is an obligation to deliver allowances equal to emissions that have been made. This liability is a provision within the scope of AASB 137 Provisions, Contingent Liabilities and Contingent Assets; A reduction in the cash flows expected to be generated by certain assets due to the requirements of emissions trading schemes requires those assets to be tested for impairment in accordance with AASB 136 Impairment of Assets (UIG, 2005). The AASB withdrew this standard subsequent to IFRIC 3's withdrawal, with no justification provided. 
Mookdee, T. - Bellamy, S.: Asset Classification, Subsequent Measurement and Impairment Testing for Carbon Emission Trading.

Since 1993, FERC, as a regulator of energy utilities, has required US electric public utilities and licensees, natural gas pipeline companies, oil pipeline companies, and centralized service companies within its jurisdiction to maintain their books and records in accordance with the Commission's Uniform System of Accounts (USofA). The USofA consists of account descriptions, instructions, accounting definitions and Account Codes that are useful in understanding the information reported in the Annual and Quarterly Report Form (FERC, 2010). As of June 2010, the USofA is the only accounting guideline for GHG emissions within generally accepted accounting principles (US GAAP) and FERC is the only organization that has issued emissions allowances accounting guidelines. Some EU ETS participants have currently adopted this guideline as well (Veith et al., 2009).

The key points covered in these guidelines are: Public utilities owning emissions allowances, other than those acquired for speculative purposes, shall account for such allowances at cost in the Allowance Inventory account or the Allowances Withheld account, as appropriate; Allowances acquired for speculative purposes and identified as such in contemporaneous records at the time of purchase shall be accounted for in the Other Investments (Assets) account; When purchased allowances become eligible for use in different years, and the allocation of the purchase cost cannot be determined by fair value; the purchase cost allocated to allowances of each vintage shall then be determined through the use of a presentvalue based measurement. The interest rate used in the present-value measurement shall be the utility's incremental borrowing rate, in the month, in which the allowances are acquired, for a loan with a term similar to the period that it will hold the allowances and in an amount equal to the purchase price; The underlying records supporting the Allowance Inventory account and the Allowances Withheld account shall be maintained by providing sufficient detail in order to show the number of allowances and the related cost by vintage year; Issuances from inventory include the Allowances Inventory account and Allowances Withheld account, which should be accounted for on a vintage basis using a monthly weighted-average method of cost determination. The cost of eligible allowances not used in the current year should be transferred to the vintage for the following year; The Allowance Inventory account should be credited and allowances (unremitted account,) debited so that the cost of the allowances to be remitted for the year is charged to monthly expenses based on each month's emissions. This may, in certain circumstances, require an allocation of the cost of an allowance between months on a fractional basis; in any period in which actual emissions exceed the amount allowable based on eligible allowances owned, the utility shall estimate the cost to acquire the additional allowances needed and charge the Allowances Inventory account with the estimated cost. This estimated cost of 
future allowance acquisitions should be credited to the Allowances Inventory account and charged to the Allowance account in the same accounting period as the related charge to the Allowances Inventory account. Should the actual cost of these allowances differ from the estimated cost, the differences should be recognized in the then-current period's inventory issuance cost; Gains on dispositions of allowances, other than allowances held for speculative purposes, shall be accounted for by uncertainty levels as to the regulatory treatment; Losses on disposition of allowances that qualify as regulatory assets shall be charged directly to the Other Regulatory Assets account. All other losses shall be charged to the Losses from Disposition of Allowances account. Gains or losses on disposition of allowances held for speculative purposes shall be recognized in the Miscellaneous Non-operating Income or Other Deductions account, as appropriate (FERC, 2010).

The World Resources Institute and the World Business Council for Sustainable Development's Greenhouse Gas Protocol and its tailored guidelines provide GHG accounting principles for financial accounting and reporting, intended to underpin and guide GHG accounting and reporting to ensure that the greenhouse gas inventory constitutes a faithful, true, and fair account of a company's GHG emissions. The principles are derived partly from the generally accepted accounting principles of Relevance, Completeness, Consistency, Transparency and Accuracy. The protocol also identifies 5 business goals as providing the rationale for compiling a GHG inventory: managing GHG risks and identifying emissions reduction opportunities; public reporting and participation in voluntary GHG programs; participation in mandatory reporting programs; participation in GHG markets; and recognition for early voluntary action. The protocol has been designed as a comprehensive GHG accounting and reporting framework to provide information capable of serving business goals relating to emissions reduction and reporting (WRI, 2004).

The US Federal Greenhouse Gas Accounting and Reporting Guidance (October 2010) is the latest set of guidelines issued by an environmental government agency, and aims to make the reduction of GHG emissions a priority for Federal agencies. It follows the basic guidelines of GHG Protocol for the U.S. Public Sector (PSP). Similar to the GHG protocol discussed earlier, this guideline provides information on: how to set organizational and operational boundaries; the scope of emissions; sequestration and emissions from land use, agriculture, and biogenic sources, renewable energy and carbon offsetting; reporting GHG emissions; and verification and validation of GHG emissions. In addition to the above protocol, a tailored guidance for the public sector was released by the WRI in October 2010: The Greenhouse Gas Protocol for the U.S. Public Sector: Interpreting the Corporate Standard for U.S. Public Sector Organizations (PSP). 
Mookdee, T. - Bellamy, S.: Asset Classification, Subsequent Measurement and Impairment Testing for Carbon Emission Trading.

The PSP aims to offer flexibility to its public sector report preparers by establishing certain core principles and quantifying methodologies that ensure relevance, completeness consistency, transparency, and accuracy of GHG inventory. Its content is compatible with the original protocol; the only significant difference relates to its focus on the public sector.

The WRI and WBCSD's Greenhouse Gas Protocol, a Corporate Accounting and Reporting Standard, is a widely accepted and adopted international accounting guideline that provides the accounting framework for nearly every greenhouse gas standard and program in the world. This protocol identifies 5 business goals as reasons for compiling a GHG inventory, and provides guidelines for organizations to define their goals clearly. The protocol also provides managerial accounting guidelines in quantifying and managing GHG emissions, such as the setting of organizational and operational boundaries, tracking GHG emissions over time, and identifying and calculating GHG emissions.

Thus, only US-based guidelines provide detailed instructions in quantifying and managing GHG emissions based on these boundaries. These instructions assist entities in avoiding uncertainty regarding the accuracy of the emission volumes and provide useful information to management about those volumes.

In the absence of formal guidelines on accounting for carbon emissions trading, financial report preparers have been able to draw on existing accounting standards based on a conceptual framework, on interpretations and analyses by experts, and/or on their own knowledge and experience in reporting on carbon emissions trading. It is hardly surprising that, in practice, accounting for emissions allowances has been found to lack consistency (Elfrink \& Ellison, 2009).

The EU ETS has created a number of issues that have accounting ramifications such as the free allocation and purchase of certificates, the due date for surrendering not coinciding with the fiscal year end of regulated emitters' financial reporting, holding and trading gains/losses, and a number of others (Veith at al., 2009). Several studies have explored the financial reporting practices of ETS participants. In 2007, the International Emissions Trading Association (IETA) ${ }^{2}$ and PricewaterhouseCoopers $(\mathrm{PwC})$ conducted a European-wide survey of accounting approaches used by 26 major organisations significantly affected by the EU ETS and the Kyoto Protocol. This survey aimed to present a synopsis of the accounting approaches adopted and to understand the key themes and issues arising in the absence of specific accounting guidelines. They reveal the uncertainty and diversity of the accounting practices of the 26 European

2 IETA is an independent, non-profit organisation dedicated to the establishment of effective systems for businesses to trade in greenhouse gas emissions. 
companies concerned: Only a small number of respondents continued to use the withdrawn IFRIC 3 Emissions Rights as their accounting policy; The most common approach identified was initial recognition of granted allowances at nil value as intangible fixed assets in the balance sheet. Purchased allowances were recognised in the same way. These granted/purchased allowances were not subsequently amortized or depreciated, neither were they re-valued subsequent to initial receipt and purchase; Where granted allowances were initially recorded at fair value and deferred income was recognized, half of the respondents released deferred income to the income statement in line with the emissions produced in that period. A third of them released deferred income to the revenue line, a third to the cost of sales and the remainder to some other line; In valuing obligations associated with the production of emissions, most respondents based this on the carrying value of those allowances already granted (which may be nil) and purchased, with the balance of the obligation valued at the prevailing market price; Where granted allowances initially recorded at nil value were sold, the gain on disposal was recognized immediately as a credit to the income statement; Most respondents recognized the sales of allowances within cost of sales (netting sales proceeds against cost of sales effectively represents a reduction of the cost of compliance with the EU ETS); Forward contracts for purchased/granted allowances are deemed to be within the scope of IAS 39 Financial Instruments: Recognition and Measurement, which applies to contracts for buying or selling a non-financial item; these contracts can be settled net in cash or another financial instrument or by exchanging financial instruments; Forward contracts are fair valued through income statements; Nearly half of all respondents reported under accounting standards other than just IFRS, with most also reporting under US GAAP.

In addition, in 2010 the Association of Chartered Certified Accountants (ACCA) ${ }^{3}$, working in partnership with IETA, conducted a survey of the financial statements of the largest GHG emitters in the EU ETS (26 companies) in order to establish a baseline understanding of current accounting practices. It also aimed to uncover opinions on how to resolve the absence of accounting guidance for emissions allowances as well as to explore the theoretical implications of the research findings. This was followed by telephone interviews with accountants at 5 of these companies to explore in detail, the reasons for the firm's accounting practices. The findings reveal that: There is considerable diversity in accounting practices for EU ETS emissions allowances; Most companies are not following IFRIC 3; Some elements of IFRIC 3 appear to have influenced accounting practices adopted, with 11 of the 26 companies treating emissions allowances as intangible assets; A third of these assets are mostly assigned a nil value in company accounts, reflecting the

The ACCA is a UK-based global body for professional accountants. 
Mookdee, T. - Bellamy, S.: Asset Classification, Subsequent Measurement and Impairment Testing for Carbon Emission Trading.

fact that in Phase 1 and 2 of the EU ETS, allowances have predominantly been allocated at no charge; Only a small number of companies follow the withdrawn IFRIC 3 guidance by accounting for emissions allowances initially at fair value (that is, at market price), with the difference between fair value and cost recognised as a governmental grant (deferred income) on the balance sheet; Most companies do not disclose any information on amortisation/depreciation, and half the surveyed companies fail to disclose data on the revaluation of emissions allowances; Most of the surveyed companies account for their obligations by following a 'cost with balance at market value' approach.

Research exploring the underlying reasons for accounting policy choices regarding carbon emissions by market participants is very limited. Only one survey, conducted by Lovell, et al. (2010), has uncovered such underlying reasons.

"We believe that the European Community [SIC] has to define, to clearly define, the nature of the emission [allowance]. Because... the standard setter [does not have a]...duty...to identify what is a legal point of view or a tax point of view. They are not legal setters...But the accounting approach cannot arise before the identification of the legal nature." (Head of accounting principles and standards, large European energy company), Lovell et al. (2010).

Turning now to the US situation, accounting issues relating to past and current usage of emissions allowances have been identified broadly by Elfrink and Ellison (2009) as: Asset Valuation and Classification: Inventory, Intangible Assets, Marketable Securities and Investment; Effects on the Income Statement: Expensing; Reporting of Liabilities; Recognition of Government Grants; Appropriateness in Re-valuation of Related Assets and Liabilities; Accounting for Sales of Participants; Effects on the Statement of Cash Flows. The issues identified can be seen in US surveys on accounting practices related to emissions allowances. In a 2010 survey of US public registrants with revenues between $\$ 1$ billion and $\$ 100$ billion for annual filings occurring between 1 February 2009 and 13 September 2009, it was found that 29 companies disclosed an accounting policy related to emissions credits or allowances in the notes to their financial statements. Almost 40 per cent of them recognised emissions allowances as intangible assets, one-third as inventory and less than one-fifth as regulatory assets/liabilities and other (Ernst\&Young, 2010). The surveys' findings could be strengthened by the conduct of a longitudinal study.

A survey conducted by the Financial Accounting Standards Board (FASB) suggests that most US entities generally account for emissions allowances in a manner similar to that required by FERC regulation. The majority of companies currently classify emissions allowances held as either intangible assets and/or 
inventory, although there were other classifications entertained such as financial assets in the initial draft of EITF 03-14 (Deloitte, 2009).

In the US cap-and-trade program, emissions allowances each have a vintage year designation indicating the first year an allowance may be used. A surplus of allowances in this year can be carried forward to accommodate future demand. Allowances with the same vintage year are exchangeable and can be remitted from any source; a shortfall in the current year may be covered by emissions allowances from a new emissions reduction project from the next year. Thus, there is a diversity in practices regarding liability and gain recognition in US emissions markets (Ernst\&Young, 2010).

In the UK, Balatbat and Wang (2010) used the data from the first phase of the UK EU ETS to examine the current state of financial reporting of carbon emissions permits in the cap-and-trade scheme prior to the release of accounting standards or authoritative guidance. The annual reports of 159 UK entities exposed to EU ETS were examined to reveal 21 entities providing voluntary disclosures of their accounting policies on carbon emissions allowances. Content analysis revealed that among small disclosing firms, numerous accounting policies were adopted with respect to accounting for the allocation, purchase and sale of emissions allowances and the recognition of carbon emissions liabilities. Those disclosing accounting policies were not comparable.

The key issues were as follows: More than half of the sample entities classified emissions permits as assets (intangible asset and inventory); Valuation bases for emission permits were either 'nil' cost or fair value; Allocated emissions permits were identifiable non-monetary assets without physical substance that met the definition of IAS38 Intangible Assets; Nearly half of the sample entities did not disclose their accounting policy on the sale and purchase of emissions allowances. Those entities that disclosed reported emissions permits in response to the Carbon Disclosure Project. ${ }^{4}$ There were some ambiguous disclosures in regards to carbon emissions permits. The following findings are consistent with those of the 2007 survey conducted by PwC and IETA: Larger entities considered the transactions on carbon emissions permits to be immaterial; the energy sector was wellrepresented in the sample, followed by the electricity and material sectors; $95 \%$ of sample entities were audited by the Big 4 audit firms. It is noted that the study focused on the emitters' perspective and used voluntarily disclosed secondary data. There were no in-depth interviews conducted to establish the underlying reasons why sample entities chose particular accounting policies.

4 The Carbon Disclosure Project (CDP) works with 3,000 of the largest corporations in the world to help them ensure that an effective carbon emissions/reductions strategy is made integral to their business. 
Mookdee, T. - Bellamy, S.: Asset Classification, Subsequent Measurement and Impairment Testing for Carbon Emission Trading.

Steenkamp et al. (2011) examined 18 liable European entities who disclosed their accounting practices in their annual accounts. The key findings are as follows: $61.11 \%$ of sample companies did not disclose policy in recognition of their granted allowances, while one-third of them initially recognized granted allowances as intangible assets; $61.11 \%$ of sample companies did not disclose policy in recognition of their purchased allowances, while the rest of them initially recognized purchased allowances as intangible assets; $72.22 \%$ of sample entities valued granted allowances at nil value, the rest valued them at market and fair value; $38.88 \%$ of sample entities valued purchased allowances at nil value, $22.22 \%$ of these liable entities valued them at market and fair value; $33.33 \%$ of liable entities recognized granted emissions allowances in correspondence with the Government Grant account, and 5.55\% in correspondence with Provision and Liabilities account; $33.33 \%$ of liable entities recognized purchased emissions allowances in correspondence with Provision and Liabilities account. Also, this study examined secondary data and there were no underlying reasons for these accounting practices. The other survey conducted in Europe was carried out by Warwick and $\mathrm{Ng}$ (2012).

Warwick and $\mathrm{Ng}$ (2012) surveyed accounting practices from 47 liable emitters according to EU ETS. The key issues are as follows: The most common initial recognition for granted allowances is intangible asset (55.3\%) while more than one-third of the sample companies did not disclose their practices; The most common applicable value for granted allowances are nil value $(38.3 \%)$, fair value (21.3\%) and nominal value $(6.4 \%)$; The most common initial recognition of purchased allowances is not prevailing explicitly but the most common valuation is at cost; $80.8 \%$ did not disclose subsequent measurement of both granted and purchased allowances; The most common recognition of obligation is provision/liability $(78.7 \%)$ and expense $(4.3 \%)$. It is clear that this study was conducted using secondary data, as the underlying reasons for these accounting practices were not available.

It is clear that the complexity of accounting for emissions trading is attributed to the unclear purpose, from the emitter's perspective, in holding carbon credits or emissions allowances. Liable entities in Europe under a cap-and-trade program could hold their granted and purchased allowances either for surrendering or for sale. Liable entities in Australia under GGAS can hold created carbon credits and purchased carbon credits either for sale or for surrendering. However, similarly to the survey result, Warwick and $\mathrm{Ng}$ (2012), KPMG's recommendations support the idea that liable entities should recognize assets in correspondence with provision or liability (KPMG, 2012). In addition, there is no created emissions allowance under the European Emission Trading Scheme. All emissions allowances are not the main products of each entity, they are the by-products. Thus, these surveys 
uncover the facts that there was no subsequent measurement or revaluation of these emissions allowances, and consequently disclosure of impairment testing prevailed (IETA/PWC, 2007; Lovell et al., 2010; Balatbat \& Wang, 2010; Steenkamp et al. 2011; Warick \& Ng 2012). Moreover, a survey conducted by Gallego-Alvarez et al. (2016) show that different emitters's accounting treatments are determined by legislation in their counties of origin. Sample companies from this survey tend to account for emission rights through provisions, investments or as inventory. However, there is no evidence found from Australian correspondent.

In order to determine which model should be applied for emissions allowances, many entities consider how emissions allowances have been used previously, their prospective intent and the accounting ramifications of each model (Deloitte, 2009). In the Australian context, it is conceivable that ACPs who are benchmark participants might want to utilize different accounting models for different sources of abatement certificates - for example, treating abatement certificates held for surrendering as intangible assets and those held for sale as inventory. Supporters term this approach a 'hybrid' one that requires further evaluation such as operational, organizational boundary and compliance consistency (Deloitte, 2009).

Moreover, in 2013-2014, the Australian Securities and Investment Commission (AISC) defined EU emission allowances, carbon units and all types of abatement certificates as financial products but ceased them later on in 2015, ASIC (2015).

From the foregoing literature review, it is clear that the following accounting issues are critical; they will therefore be taken to the design of the interview questions.

- Asset recognition and classification

- Applicable value and valuation

- Impairment Testing (as a consequence of intangible asset recognition)

\section{Data and Methodology}

The term "carbon credits", "carbon offsets", “ emission allowances" (in Europe) and "NSW Greenhouse Abatement Certificates, NGACs" (in Australia) are used interchangeably in this paper. In addition, the study is concerned with financial accounting for emissions trading activities only. Managerial issues relating to quantification of carbon dioxide, abatement auditing and reporting, emitter's surrendering activities as required by GGAS, Kyoto Protocol or other emission trading schemes worldwide are not addressed. 
Mookdee, T. - Bellamy, S.: Asset Classification, Subsequent Measurement and Impairment Testing for Carbon Emission Trading.

The research questions are as follows:

- How do the forest carbon credit providers in Australia account for carbon emissions trading and abatement certificates in their annual financial statements?

- Why are the forest carbon credit providers motivated to choose a particular accounting method to report emissions trading activities and carbon credits in their annual accounts?

- What constitutes emerging good practices in accounting for carbon emissions trading drawing on experts' opinions?

Data collection consists of 3 phases:

- Secondary data collected online from notes to the financial statements of carbon credit providers who perform forest carbon sequestration. Basic information from registered/accredited carbon credit providers was downloaded from the GGAS registry and their website and categorised by accreditation. Financial statements of carbon credit providers from 2005-2012 were collected. However, these accounting policies are collected only when voluntarily disclosed in their notes to financial statements. The information derived is categorised by accounting issues derived from literature review.

- Primary data collected from in-depth interviews of carbon credit providers' CFO delegates, senior accounting persons and accountants. Those short listed were selected by the criterion determined in the introduction. The duration of each interview is about 1-1.5 hours per person in order to encourage a perfect recall and enlightenment of interviewees. Voice recording, place, date and time of interview were arranged from interviewees' permission and preference. The primary data were transcribed and assigned codes and analysed using NVIVO software. This software helps to organise unstructured audio information and to analyse findings effectively. Common, recurrent and emergent regularities are defined and provided systematically for expert interview in the next phase.

- Primary data was collected from in-depth interviews with financial accounting experts. The expert interviewees are made up of 5 accounting scholars from Australian Universities and 1 auditor from a well-known audit firm. The academics are experts in financial reporting and have publications in carbon market-related accounting issues. The auditor has had extensive experience in auditing, financial reporting and taxation. Again, the duration of each interview was between 1 and 1.5 hours in order to facilitate recall. Voice recording, place, date and time of the interviews were arranged from interviewees' permission and preference. Linking with data derived in the second phase, primary data in the third phase were analysed using NVIVO software and convergence or content analysis to find out regularities, commonalities and 
emerging good practice (if any). The primary data collected from experts is analysed in a separate paper.

\section{Results and Discussion}

The company in the mandatory market is denoted as Company $\mathrm{M}$, the one from both markets is denoted as Company $\mathrm{H}$ (Hybrid) and the last one from the voluntary market is denoted as Company $\mathrm{V}$. These forest companies are operating in 4 major business activities such as environmental credit trading, sales of forest carbon credit, carbon planting and advisory service.

\subsection{Research question 1 (archival data)}

The partial archival data of carbon credit-related accounting policy from fiscal years 2005-2012 of 3 companies is presented together with interview excerpts in the next subsection.

\subsection{Research question 2 (in-depth interviews)}

Underlying Reason of Forest Carbon Credit Providers to address Research Question 2: Accountant interviewees from Company $\mathrm{M}, \mathrm{H}$ and $\mathrm{V}$ were asked about the following topics:

\subsubsection{The qualitative characteristics of accounting information for carbon emission trading:}

M's Carbon credits were accounted for as part of inventory and carbon sinks were accounted for as non-current biological assets. This was confirmed in interviews. M's carbon credit trading is a very minor segment of Company M. All 3 interviewees pointed out that "Relevance and Reliability"are the key qualitative characteristics of accounting information because they are under the AGAAP. ${ }^{5}$

Interviewees from Company $\mathrm{H}$ explained that "Reliability and Understandability" are the core qualitative characteristics of accounting information because there is a science behind it all. That science is well known in its discourse community. Also, the methodology of quantification is well understood by people in its discipline and it is approved by the scheme administrator. However, the concept of comparability in the unit of production basis of each provider is not likely to be applicable since there are more choices of method approved by the scheme administrator. These choices of method would make a difference to its financial reporting and accounting policy.

5 AGAAP stands for Australian General Accepted Accounting Principle. 
Mookdee, T. - Bellamy, S.: Asset Classification, Subsequent Measurement and Impairment Testing for Carbon Emission Trading.

One interviewee from Company $\mathrm{H}$ raised a concern about real transparency around internally-generated carbon credits, as they will be off balance sheet. The stock "are just lurking around". However, the carbon credits created are verifiable by the regulator since they are cross-checked and signed off by the independent forest auditor.

The senior accounting management from Company $\mathrm{V}$ maintains that verifiability, comparability and reliability are the qualitative characteristics of accounting information related to carbon emission trading. Also, verifiability is problematic because the company plants are very large scale.

\subsubsection{Asset Type of Carbon Credits}

There was no monetary value of carbon credits in Company M's financial statements since the estimation cannot be made reliably. In the interviewees' view, carbon credits must be treated as inventory under the AGAAP (Australian General Accepted Accounting Principle). It is assumed that carbon credits are included in finished goods in archival data. However, one interviewee from Company $\mathrm{M}$ also believes that carbon credits are invisible; they could be financial instruments because they can be traded. Institutional theory would recognise this as a coercive factor from existing accounting standards exerted on Company M's accounting policy.

During 2005-2012, Company H's disclosure and classification, was attributing to the state of plantation under foresters' control. Company $\mathrm{H}$ were planting on behalf of customers and it will not stock carbon credits directly. Therefore $\mathrm{H}$ defines unregistered carbon credits under plantation condition as "carbon sinks under development".

\section{Tab. 1 Summary of H's Carbon Credit Classification}

\begin{tabular}{ll}
\hline Year & Carbon credits \\
\hline 2005 & None \\
2006 & None \\
2007 & Other current assets \\
2008 & Purchased carbon credits-Other current assets \\
2009 & Purchased carbon credits-Other current assets \\
2010 & Purchased carbon credits-Other current assets \\
2011 & Purchased environmental credits-Other current assets \\
2012 & Purchased environmental credits-Other current assets \\
\hline
\end{tabular}

Source: Project's interviews. 
$\mathrm{H}$ does not have a big bank of carbon credits. An interviewee maintained that the group treats generated carbon credits and purchased carbon credits as other current assets. Moreover, $\mathrm{H}$ has a minor segment which is a trading business. They treat both created and purchased carbon credit, as well as other renewable energy certificates, as financial instruments. The revaluation or subsequent measurement therefore, is applicable/allowed by the nature of the FVTPL financial instruments.

This is the coercive factor from the nearest existing accounting standard. However, in revaluation, the qualified trader, the director and the accountant have to refer to the market rate or spot rate from the "Green Room" as described in the next section. This subsequent measurement, FVTPL, is similar to an opinion from Houpt and Ismer (2011) when the carbon credits are held for sales.

These created, purchased credits and renewable energy certificates are treated like a financial instrument and they have been traded in the spot market. H's senior accounting personnel maintains that:

"Because we currently trade large and small renewable energy credits, these credits from carbon will be treated, will be created in a very similar way to the credits created under renewable energy credit block."

Tab. 2 Summary of V's Scope of Inventory

\begin{tabular}{ll}
\hline Year & Inventory \\
\hline 2008 & Stock on hand (Carbon Development Expenditure) \\
2009 & Inventories (Carbon Emission Reduction) \\
2010 & Inventories (Plantations-at Cost) \\
2011 & Inventories (Plantations) \\
2012 & Inventories (Plantations-at Cost and seed stock- at cost) \\
\hline
\end{tabular}

Source: Project's interviews.

The senior accountant interviewee explained the underlying reasons for the accounting policy in inventories is that the various wordings changed along this 5year time span are because of the nature of new business and changes in law and regulation.

\subsubsection{Applicable Value}

Company $\mathrm{M}$ never recognises the monetary value of carbon credits in its financial statements. Carbon credits are included as finished goods under inventory. The inventory is stated as the lower of cost or net realisable value. M's interviewee pointed out the underlying reasons for this policy as follow: "It's really a sort of inventory standard. We haven't gone into other conception. We've just follow the 
Mookdee, T. - Bellamy, S.: Asset Classification, Subsequent Measurement and Impairment Testing for Carbon Emission Trading.

standard that we have and some audit advice; we really haven't sorted on anything else. We actually use the easiest method as possible."

For Company $\mathrm{H}$ to go back to the basic accounting principle, its inventory valuation is presented in table 3 .

The interviewee from Company $\mathrm{H}$ maintains that it is just straightforward accounting and a straightforward policy. The purchased credits and renewable energy certificates are treated like a financial instrument and they have been traded in the spot market. Revaluation is needed and will be recognize by Fair Value Through Profit and Loss (FVTPL).

\section{Tab. 3 Summary of H's Carbon Credit Valuation}

\begin{tabular}{ll}
\hline Year & Carbon credits \\
\hline 2005 & None \\
2006 & None \\
2007 & Historical Cost \\
2008 & Purchased Carbon credits -Fair value \\
2009 & Purchased Carbon credits -Fair Value \\
2010 & Purchased Carbon credits -Fair Value \\
2011 & Purchased environmental credits-Fair Value Through Profit and Loss (FVTPL) \\
2012 & Purchased environmental credits-Fair Value Through Profit and Loss (FVTPL) \\
\hline
\end{tabular}

Source: Project's interviews.

These created, purchased credits and renewable energy certificates are treated like a financial instrument and they have been traded in the spot market: "Because we currently trade large and small renewable energy credits, these credits from carbon will be treated, will be created in a very similar way to the credits created under renewable energy credit block." In addition, the second interviewee from $\mathrm{H}$ argued that carbon credits are not inventory. They are traded electronically by the company's qualified trader who has AFSL (Australian Financial Service License). This follows IAS 39 or AASB 139 Financial Instruments: Recognition and Measurement and ASIC (2012).

"The valuation is based on the publication called 'Green Room' which is at the end of each week and quotes the spot rate of all the items. You have to subscribe to it. We have a middle office, the trader has got market rate, spot rate in our system. We do market-to-market every week and prepare a report every month. The trader monitors it on daily basis actually because they have to buy and sell 
buy and sell. The trading business is what we keep separate really. It's a different segment and different business."

The role of the accountant is to prepare sufficient funds for them to make a deal approved by the directors. This subsequent measurement, FVTPL, is similar to an opinion from Houpt and Ismer (2011) when the carbon credits are held for sales.

According to the interviewee from Company V, tree planting is an agricultural activity. Agricultural products from harvest point are accounted for as inventory in accordance with IAS2 (AASB 102) Inventory. Company V recognised inventories at the lower of cost or net realisable value. In 2008-2009, the group defined the inventory costing method but from 2010-2012, the policy was changed as follows.

\section{Tab. 4 Summary of V's Inventory Valuation}

\begin{tabular}{ll}
\hline Year & Inventory \\
\hline 2008 & $\begin{array}{l}\text { The lower of cost and net realisable value/ First-in First-out base, determined by } \\
\text { Weighted-average method }\end{array}$ \\
& $\begin{array}{l}\text { The lower of cost and net realisable value/ First-in First-out base, determined by } \\
2009\end{array}$ \\
2010 & Weighted-average method \\
2011 & The lower of cost and net realisable value \\
2012 & The lower of cost and net realisable value
\end{tabular}

Source: Project's interviews.

Also, the interviewee defined reference from "Treasure Modelling" to calculate net realisable value and to re-evaluate its plantations in 2010-2012.

\subsubsection{Impairment Testing}

$\mathrm{H}$ has a policy on impairment testing of assets related to carbon emission trading but there is no impairment loss/charge of carbon sinks or intangible assets recognised at the moment. However, carbon sinks recognised as Property, Plant and Equipment are written-off to match with revenue every year, while trees are also growing. $\mathrm{H}$, therefore, never recognises impairment but reviews it annually. Also, H's auditor and audit committees are people who determine impairment of asset. However, the interviewee maintains that impairment testing is the accountant's responsibility:

"It's based on Treasury Modelling ${ }^{6}$ looking forward carbon price. We look at what treasury thinks how the carbon price is going to go. That's the important argument in terms of what we are going to produce from the foresters. We don't mess

6 Federal Government's the Treasury Modelling informs policy design and public discussion about carbon pricing. A range of scenarios which explore different environmental targets and design features of a carbon pricing scheme are provided by the treasury 
Mookdee, T. - Bellamy, S.: Asset Classification, Subsequent Measurement and Impairment Testing for Carbon Emission Trading.

around changing that too much. We started with the one curve of production and we are staying with that."

However, as mentioned by the second interviewee of $\mathrm{H}$, that they are beneficiaries of the "Green Room", international trading platform of carbon markets. The price index of carbon credits, regardless of origins, therefore, is monitoring by all market participants. The further study of impairment testing method for emission allowances is a must.

\section{Tab. 5 Summary of H's Impairment testing of assets}

\begin{tabular}{ll}
\hline Year & Impairment testing of assets \\
\hline 2005 & Yes \\
2006 & Yes \\
2007 & Yes \\
2008 & Yes \\
2009 & Yes \\
2010 & Yes \\
2011 & Yes \\
2012 & Yes \\
\hline
\end{tabular}

Source: Project's interviews.

\section{Conclusion}

The preferred accounting treatment of each firm relies on coercive factors such as rules, regulations and general accounting standards (IAS 2 or AASB 102 Inventory, IAS 39 or AASB 139 Financial Instruments). Unlike prior studies in the $\mathrm{EU}$, the preferred initial recognition of carbon credits (emission allowances) is not as an intangible asset but impairment testing is essential.

Besides the government's rules and regulations, there is evidence that the accounting practices of forestry carbon credit providers rely greatly on the forestry profession and accounting estimates are all made by foresters. However, carbon credits, regardless of origins or types, can be traded internationally like financial commodities. References from international trading platforms and participating governments are necessary for impairment testing.

In order to access the in-depth full set of data, this study focuses on case companies who have been developing accounting systems on these issues. Thus, the limitation relates to the limited number of sample companies. In conclusion, there is a need for further study to be done to establish more valid results. In addition, international accounting policy makers and professional accountants 
need to address these issues to improve the quality of the accounting information and to promote standardization of accounting practice for carbon emission trading worldwide.

\section{References}

Australian Securities and Investments Commission (ASIC), 2012. Regulatory Guide 236: Do I need an AFS license to participate in carbon markets? Australia, Available from: <http://asic.gov.au/regulatory-resources/find-a-document/ regulatory-guides/rg-236-do-i-need-an-afs-licence-to-participate-in-carbonmarkets/>. [25 August 2012].

Australian Securities and Investments Commission (ASIC), 2015. Carbon markets Updated regulatory guidance, Australia. Available from: <http://asic.gov.au/ regulatory-resources/financial-services/carbon-markets/>. [5 December 2015].

Balatbat, M., Wang, W., 2010. Voluntary disclosure of accounting policies for the treatment of carbon emission permits: The UK EUETS case', in GECAMB 2010: Corporate Social and Environmental Accounting Management Conference, Leiria, Portugal, October 14-15, 2010, Centre for Social and Environmental Accounting Research (CSEAR), Scotland, 1-30.

Deloitte \& Touche (Deloitte), 2009. Carbon Accounting Challenges: Are you ready? Deloitte Center for Energy Solutions, Washington D. C., US.

European Financial Reporting Advisory Group (EFRAG), 2005. Re: Adoption of IFRIC 3 Emission Right, Brussels, Belgium. Available from: <http://ec.europa.eu/ internal_market/accounting/docs/ias/efrag/efrag-2005-05-endorsementletter_en.pdf>. [2 January 2011].

Elfrink, J., Ellison, M., 2009. Accounting for Emission Allowances: An Issue in Need of Standards. The CPA Journal 79, 68-71.

Emerging Issues Task Force (EITF), 2003. EITF Abstract: Issue No.03-14, Financial Accounting Standards Board, USA.

Gallego-Alvarez, I., Martínez-Ferrero, J., Cuadrado-Bellesteros, B., 2016. Accounting Treatment for Carbon Emission Rights, Systems 1, 1-15. DOI: $10.3390 /$ systems 4010012 .

Houpt, M., Ismer, R., 2011. Emissions Trading Schemes under IFRS - Towards a "true and fair view", Climate Policy Initiative, University of Erlangen-Nürnberg, Erlangen, Germany. Available from: <https://climatepolicyinitiative.org/wpcontent/uploads/2011/12/Emissions-Trading-Schemes-under-IFRS.pdf >

[20 December 2011]. 
Mookdee, T. - Bellamy, S.: Asset Classification, Subsequent Measurement and Impairment Testing for Carbon Emission Trading.

IETA, PwC, 2007. Trouble-entry Accounting, Geneva, Switzerland. Available from: <http://www.ieta.org/resources/Resources/Reports/trouble_entry_accoun ting.pdf $>$. [18 September 2010].

KPMG, 2012, Accounting for Carbon, September 2012. KPMG Insights: Blog. Available from: <http://www.kpmg.com/AU/en/IssuesAndInsights/Articles Publications/Climate-Change-Carbon-Price/Documents/accounting-for-carbonseptember-2012.pdf>. [24 October 2012].

Lovell, H., Bebbington, J., Larrinaga-Gonzalez, C., 2010. Accounting for Carbon, ACCA, London.

Raiborn, C., Massoud, M., 2010. Emissions Allowances: Accounting and Public Policy Issues, Accounting and the Public Interest 1, 105-121. DOI: 10.2308/api.2010.10.1.105.

Steenkamp, N., Rahman, A., Kashyap V., 2011. Recognition, Measurement and Disclosure of Carbon Emission Allowances Under The EU ETS-An Exploratory Study, CSEAR 2011 Australasian Conference, Tasmania, AU.

The New South Wales Greenhouse Gas Reduction Schemes (GGAS), 2010. IPART: Compliance and Operation of the NSW Greenhouse Gas Reduction Scheme during 2009 - July 2010, Australia. Available from: <https://www.ipart. nsw.gov.au/Home/Industries/Greenhouse-Gas-Reduction-Scheme/Complianceand-Operation-of-the-NSW-Greenhouse-Gas-Reduction-Scheme-during-2009July-2010>, [25August 2010].

Veith, S., Werner, J. R., Zimmerman, J., 2009, Competing Accounting Treatments for Emission Rights: A Capital Market Perspective, SSRN Electronic Journal. DOI: $10.2139 /$ ssrn. 1323810 .

Warwick, P., Ng, C., 2012. The 'Cost' of Climate Change: How Carbon Emissions Allowances are Accounted for Amongst European Union, Australian Accounting Review 1, 54 - 67. DOI: 10.1111/j.1835-2561.2011.00158.x. 